\title{
Ribosomal RNA genes in mosquitoes: localization by fluorescence in situ hybridization (FISH)
}

\author{
A. MARCHI* \& E. PILI \\ Istituto di Biologia Generale, Facoltà di Medicina e Chirurgia, Università di Cagliari, Via Ospedale 119, 09124 Cagliari, \\ Italy
}

\begin{abstract}
Fluorescence in situ hybridization (FISH) was used to localize the 18S-28S ribosomal RNA gene clusters on the chromosomes of 15 mosquito species belonging to the Anophelinae and Culicinae subfamilies. In the genus Anopheles the rRNA genes are localized on the heterochromatic arm of both sex chromosomes. The association between rRNA genes and sex determining chromosomes also applies to the homomorphic karyotype of Culicinae mosquitoes, at least in those cases in which localization of the sex locus/loci has been determined. In these species ribosomal genes are often found within or adjacent to heterochromatic regions ( $\mathrm{C}$ bands). Differences in the location of rRNA genes among and within genera suggest the occurrence of several chromosomal rearrangements during the evolution of mosquitoes.
\end{abstract}

Keywords: FISH, mosquito chromosomes, rRNA genes.

\section{Introduction}

The Culicidae family (Diptera, Nematocera) includes more than 3,000 species of mosquitoes grouped in 34 genera and three subfamilies (Knight \& Stone, 1977; White, 1980). Anophelinae and Culicinae are the largest and most important subfamilies from a medical and veterinary point of view. Cytogenetic maps based on the analysis of polytene chromosomes have played a pre-eminent role in species recognition and in the understanding of evolutionary relationships within the Anophelinae group (Kitzmiller et al., 1967; Coluzzi et al., 1979; White, 1980), but had limited application in Culicinae because of difficulties in obtaining untangled and readable polytene chromosomes. However, the recent development of molecular biology in mosquitoes (James, 1992) and the use of in situ hybridization techniques provide a powerful tool for gene mapping and the development of physical gene maps in polytene as well as metaphase chromosomes of this taxonomic group.

Ribosomal RNA cistrons have been cloned and analysed in several mosquito species. Like in all eukaryotes the $18 \mathrm{~S}, 5.8 \mathrm{~S}$ and $28 \mathrm{~S}$ rRNA genes are clustered together forming tandem units repeated hundreds of times and separated by external non-transcribed spacers. In the mosquitoes Aedes albopictus and

*Correspondence. the related species Aedes aegypti the rDNA units are repeated about 400-500 times per haploid genome (Gale \& Crampton, 1989; Park \& Fallon, 1990).

The rDNA genes are located in specific chromosome regions, the nucleolar organizers (NORs). These regions have been cytologically identified in several organisms by silver staining (Sumner, 1990). However, this technique does not seem necessarily to be specific for NORs when compared with the localization of rRNA genes by in situ hybridization (Vitelli et al., 1982; Bedo \& Webb, 1989). Moreover, silver staining does not give satisfactory results in mosquitoes, often only the centromeric cores being differentiated (Motara et al., 1985; Rao \& Rai, 1987; A. Marchi, personal observation).

In this paper we present results on the localization of the $18 \mathrm{~S}$ rRNA genes in 15 species of mosquitoes belonging to the subfamilies Anophelinae and Culicinae using fluorescent in situ hybridization (FISH).

\section{Materials and methods}

Immature stages of mosquitoes were collected at different localities in Sardinia (Italy) and U.S.A. (Table 1). Larvae of Eretmapodites quinquevittatus were from a laboratory colony established at the U.V.R.I. in Uganda.

Cephalic ganglia, gonads and salivary glands were dissected from IV instar larvae or pupae previously 
incubated in 0.1 per cent colchicine for $4 \mathrm{~h}$. Tissues were fixed in methanol:acetic acid (3:1), transferred to a clean slide with a drop of lactic acid:distilled water:acetic acid (1:2:3) for $1 \mathrm{~min}$ and squashed under a siliconized coverslip. After air drying, slides were stored at $-80^{\circ} \mathrm{C}$ until processing. Ageing of slides was obtained by storing at $37^{\circ} \mathrm{C}$ for 1 week or at $80^{\circ} \mathrm{C}$ for 4 h. Aged slides were pretreated according to Pardue (1985) with slight modifications. After treatment with RNAase $(100 \mu \mathrm{g} / \mathrm{mL}$ in $2 \times \mathrm{SSC})$ at $37^{\circ} \mathrm{C}$ for $1 \mathrm{~h}$, preparations were deproteinated with 10 per cent pepsin at $37^{\circ} \mathrm{C}$ for $10 \mathrm{~min}$, washed in $\mathrm{PBS} / \mathrm{MgCl}_{2}$, and incubated in 8 per cent paraformaldehyde for $10 \mathrm{~min}$. Denaturation of chromosomal DNA was obtained by incubation in $0.07 \mathrm{M} \mathrm{NaOH}$ for $5 \mathrm{~min}$. Slides were then dehydrated and air dried.

The probe was a subclone ( $\mathrm{pE} 2$ ) of a cloned rRNA cistron from Aedes albopictus containing the 18S rRNA gene inserted in pUC118 at the Eco site (Black et al., 1989). Labelling of the probe was obtained by nick translation (BRL kit) using bio-11-dUTP (Sigma) following the company protocol. After precipitation with ethanol with an excess of salmon sperm DNA the probe was resuspended in the hybridization mixture ( 60 per cent formaldehyde in $2 \times \mathrm{SSC}$ ) at a final concentration of $1 \mu \mathrm{g} / 150 \mu \mathrm{L}$. The probe was denatured at $75^{\circ} \mathrm{C}$ for $5 \mathrm{~min}$ and cooled on ice.

Hybridization was performed according to Speleman et al. (1990). Ten microlitres of the hybridization solution were spread on the preparations with a $22 \times 22 \mathrm{~mm}$ coverslip pretreated in $0.05 \mathrm{~N} \mathrm{HCl}$. Slides were then placed in an oven for $5 \mathrm{~min}$ and incubated at $37^{\circ} \mathrm{C}$ overnight in a moist chamber. After repeated washes in 50 per cent formamide $/ 2 \times \mathrm{SSC}(\mathrm{pH} 7)$ at room temperature, detection of the probe was achieved by treatment with fluoresceinated avidin $(5 \mu \mathrm{g} / \mathrm{mL}$ in $4 \times \mathrm{SSC}$, 5 per cent non-fat dry milk) followed by incubation with biotinylated goat anti-avidin antibody $(5 \mu \mathrm{g} / \mathrm{mL}$ in $4 \times \mathrm{SSC}, 5$ per cent non-fat dry milk) and a final incubation with fluoresceinated avidin. The slides were mounted in antifading medium and observed under a fluorescent microscope (Leitz Dialux $20 \mathrm{~EB}$ ) with the $12 / 3$ filter combination.

Table 1 Species examined and area of collection

\begin{tabular}{|c|c|}
\hline \multicolumn{2}{|l|}{ Subfamily Anophelinae } \\
\hline \multicolumn{2}{|l|}{ Genus Anopheles } \\
\hline \multicolumn{2}{|l|}{ Subgenus Anopheles } \\
\hline Species: An. petragnani Del Vecchio & $\operatorname{Sardinia}(\mathbf{I})$ \\
\hline An. labranchiae Falleroni & $\operatorname{Sardinia}(\mathbf{I})$ \\
\hline \multicolumn{2}{|l|}{ Subgenus Cellia } \\
\hline Species: An. hispaniola (Theobald) & Sardinia $(\mathbf{I})$ \\
\hline \multicolumn{2}{|l|}{ Subfamily Culicinae } \\
\hline \multicolumn{2}{|l|}{ Genus Culex (Tribe: Culicini) } \\
\hline \multicolumn{2}{|l|}{ Subgenus Culex } \\
\hline Species: $C x$. pipiens Linnaeus & Sardinia $(I)$ \\
\hline Cx. theileri Theobald & Sardinia $(I)$ \\
\hline \multicolumn{2}{|l|}{ Subgenus Maillotia } \\
\hline Species: $C x$. hortensis Ficalbi & $\operatorname{Sardinia}(\mathbf{I})$ \\
\hline \multicolumn{2}{|l|}{ Genus Culiseta (Tribe: Culisetini) } \\
\hline \multicolumn{2}{|l|}{ Subgenus Allotheobaldia } \\
\hline Species: Cs. longiareolata (Macquart) & $\operatorname{Sardinia}(\mathbf{I})$ \\
\hline \multicolumn{2}{|l|}{ Genus Aedes (Tribe: Aedini) } \\
\hline \multicolumn{2}{|l|}{ Subgenus Ochlerotatus } \\
\hline Species: Ae. caspius (Pallas) & Sardinia $(I)$ \\
\hline Ae. detritus (Haliday) & Sardinia $(\mathbf{I})$ \\
\hline Ae. mariae (Sergent and Sergent) & Sardinia $\langle\mathbf{I}\rangle$ \\
\hline \multicolumn{2}{|l|}{ Genus Eretmapodites (Tribe: Aedini) } \\
\hline Species: Er. quinquevittatus Theobald & Uganda \\
\hline \multicolumn{2}{|l|}{ Genus Orthopodomyia (Tribe: Orthopodomyiini) } \\
\hline Species: Or. alba Baker & Indiana (USA) \\
\hline Or. kummi Edwards & Arizona (USA) \\
\hline Or. pulcripalpis (Rondani) & Sardinia $(\mathrm{I})$ \\
\hline Or. signifera (Coquillett) & California (USA) \\
\hline
\end{tabular}




\section{Results and discussion}

Three species of Anophelinae and 12 species of Culicinae (Table 1) were examined using FISH. These 15 species are representative of six genera which include the largest number of species and the most important disease vectors. In all of them the $18 \mathrm{~S}$ rRNA probe from $A e$. albopictus hybridizes to only one chromosome pair $(2 n=6)$ (Fig. 1).

In the three Anophelinae the rRNA genes map on the heteromorphic, partially homologous and largely heterochromatic sex chromosomes (Figs 1, 2a-c). More precisely, the rRNA genes are located on the heterochromatic homologous part of the $\mathrm{X}$ and $\mathrm{Y}$ chromosomes. In An. labranchiae the probe hybridizes to most parts of the heterochromatic long arm of both sex chromosomes except for the paracentromeric and telomeric regions (Fig. 2a). In An. petragnani (the same Anopheles subgenus), the sex chromosomes are quite small (about 16 per cent of the haploid set) with a reduced heterochromatic arm. Hybridization occurs over the entire long arm of the $\mathrm{Y}$ chromosome and on the distal half of the $\mathrm{X}$ chromosome heterochromatic arm (Figs 1, 2b). Heterochromatin localization of the rRNA cistrons is also present in An. hispaniola (subgenus Cellia). Ribosomal RNA genes are localized on the heterochromatic long arm of both sex chromosomes except for the paracentromeric and telomeric regions (Fig. 2c), as found in An. labranchiae.

Location of rRNA genes on the sex chromosomes has also been found in Anopheles quadrimaculatus by isotopic in situ hybridization using the same rDNA probe (Kumar \& Rai, 1990). In all the Anopheles mos- quitoes so far examined, sex chromosomes have the common feature of being heterochromatic and partially homologous (White, 1980). It is quite possible that the association of rRNA genes and sex heterochromatin has been conserved throughout the Anopheles genus, which includes the majority of anopheline species. Correlation between ribosomal genes and sex heterochromatin is also confirmed by the amount of hybridized rDNA probe, and consequently of rRNA genes copy number, which is proportional to the amount of heterochromatin present on the sex chromosomes.

In Culicinae species sex chromosomes are morphologically indistinguishable. However, for the species in which localization of the sex locus is known by studies on induced aberrations or in which sex chromosomes can be identified by banding techniques, the rRNA genes map on the sex chromosomes.

In Culiseta longiareolata the sex chromosomes correspond to the longest chromosome pair and can be distinguished by C- and Q-banding (Mezzanotte et al., 1979). The rRNA genes hybridize to an intercalary region of the long arm on both $\mathrm{X}$ and $\mathrm{Y}$ chromosomes, adjacent to the $\mathrm{C}$-positive paracentromeric heterochromatin (Figs 1, 2d).

In Culex pipiens, the sex locus has been localized on the shortest chromosome (chromosome 1) (Dennhöfer, 1972). The rRNA probe hybridizes to the short arm of this chromsome, in a region proximal to the centromere (Fig. 1), in agreement with results obtained on another member of the Culex pipiens complex, $C x$. quinquefasciatus (Kumar \& Rai, 1990). Similar localization of rRNA genes is present in Culex theileri,

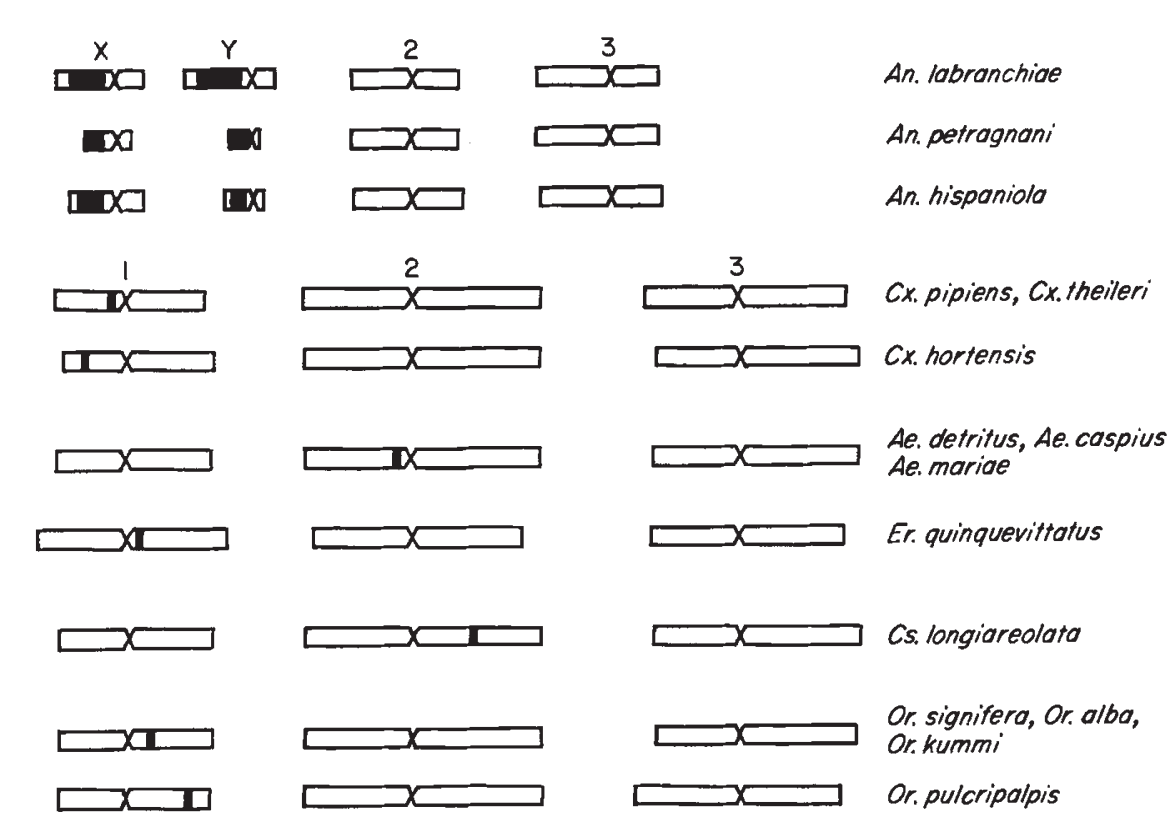

Fig. 1 Chromosomal localization of rRNA genes (dark areas) in 15 mosquito species. 


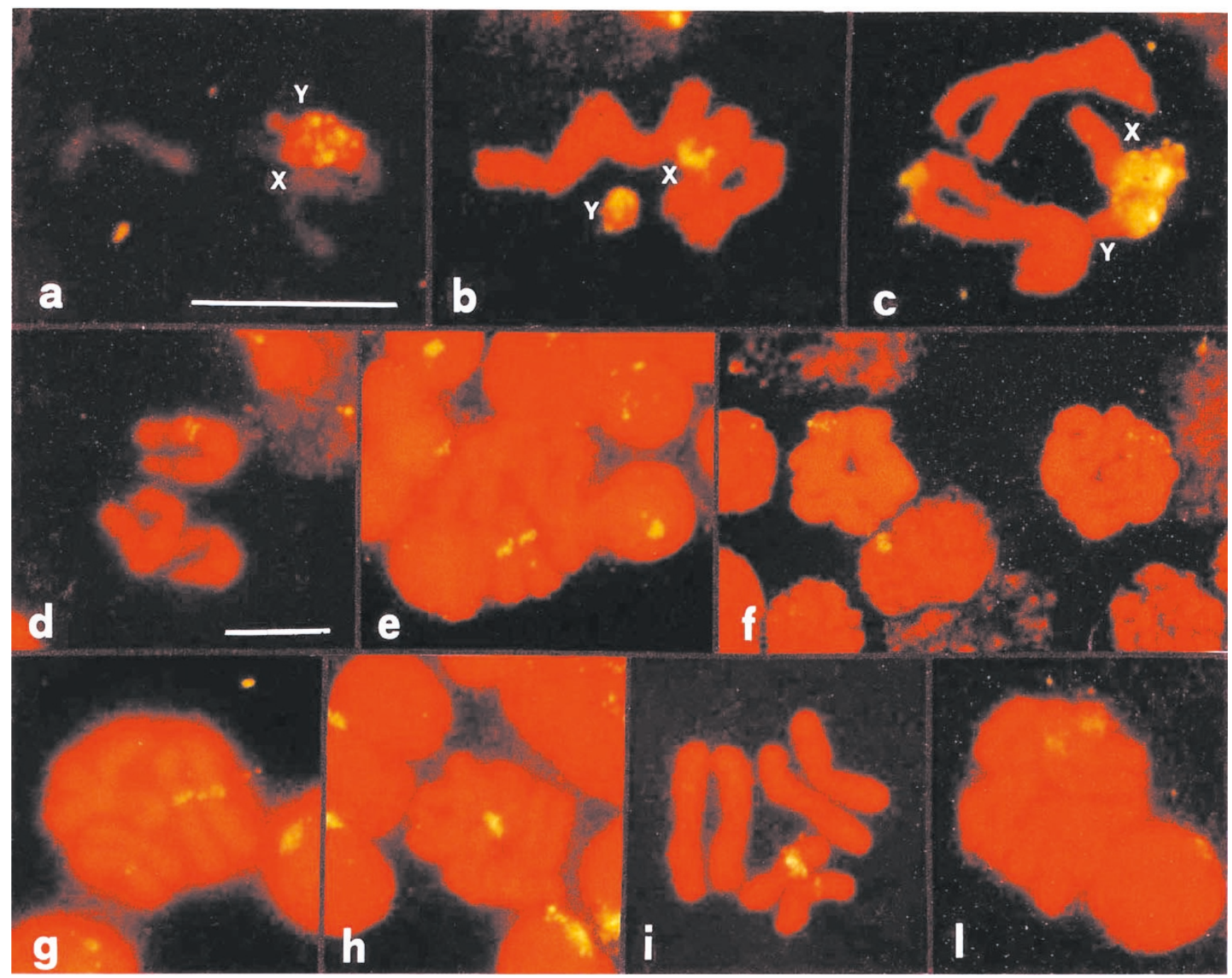

Fig. 2 In situ hybridization of the 18S rRNA probe to metaphase chromosomes of Culicidae species: (a) An. labranchiae; (b) An. petragnani; (c) An. hispaniola; (d) Cs. longiareolata; (e) Cx. theileri; (f) Cx. hortensis; (g) Ae. detritus; (h) Er. quinquevittatus; (i) Or. signifera; (1) Or. pulcripalpis. The two bars represent $10 \mu \mathrm{m}$ at different enlargements and refer to a-c and d-1, respectively.

belonging to the same Culex subgenus (Figs 1, 2e), while in Culex hortensis, subgenus Maillotia, the rRNA clusters are also on the shortest chromosome pair but in the distal third of the short arm (Figs 1, 2f). The different position of rRNA genes in these species is likely to be the result of an inversion or a transposition event that occurred during the evolution of the genus.

An analogous situation is found among the four species of Orthopodomyia (Table 1). These species are included in the same taxonomic Signifera group, on the basis of characters of adult and immature stages (Zavortink, 1968). Or. pulcripalpis is the only European representative of the group. Or. alba, Or. signifera and Or. kummi are distributed between North and Central America. In all these species the rRNA cistrons map on the shortest chromosome pair (1), within or adjacent to an intercalary $\mathrm{C}$ band. However, in the three nearctic species the localization is proximal to the centromere (Figs 1, 2i) while it is distal in the palaearctic Or. pulcripalpis (Fig. 21). This finding is in agreement with the location of the nucleolus organizer region found in polytene nuclei (Munstermann et al., 1985; Marchi, 1988). According to Zavortink (1968), the Signifera group probably originated in Middle America and then spread throughout North America and Europe. The distal location of rRNA genes in Or. pulcripalpis is probably derived from a rearrangement of the ancestral chromosome organization, retained in the nearctic species, following geographical separation of the two continents. 
Four species belonging to the tribe Aedini were analysed. In Aedes caspius, Aedes detritus and Aedes mariae (subgenus Ochlerotatus) the rRNA genes are present on the longest chromosome pair adjacent to the centromere (Figs 1, 2g). This localization is different from that found in other species of the same subgenus where the rRNA genes are present on the shortest chromosome pair (Kumar \& Rai, 1990). In Eretmapodites quinquevittatus the rDNA hybridizes to the shortest chromosome pair, close to the centromere (Fig. 2h).

Quantitative variation of hybridized probe was observed within the species examined. Individuals heterozygous for different rDNA amounts were detected in populations of Anopheles, Culex, Aedes and Orthopodomyia (Fig. 2). Variation of rRNA genes copy number at intraspecific level has been reported in several organisms (Miller, 1981; Lyckegaard \& Clark, 1989) mosquitoes included (Kumar \& Rai, 1990). Such polymorphism is probably mainly produced through recombination and unequal crossing-over (Gillings et al., 1987). In Anopheles, the partially homologous X and $\mathrm{Y}$ chromosomes undergo recombination (Sakai et al., 1979) and evidence of unequal crossing-over, often leading to differences in arm length and heterochromatin content, has been cytologically demonstrated in this genus (Marchi \& Mezzanotte, 1990).

Although localization of sex genes is not known for all the species examined, our results and those obtained by Kumar and Rai (1990) on other mosquito species strongly suggest a preferential localization of rRNA genes on the sex chromosomes, mainly within
Fig. 3 In situ hybridization of the $18 \mathrm{~S}$ rRNA probe to polytene chromosomes of (a) An. labranchiae and (b) Or.pulcripalpis.

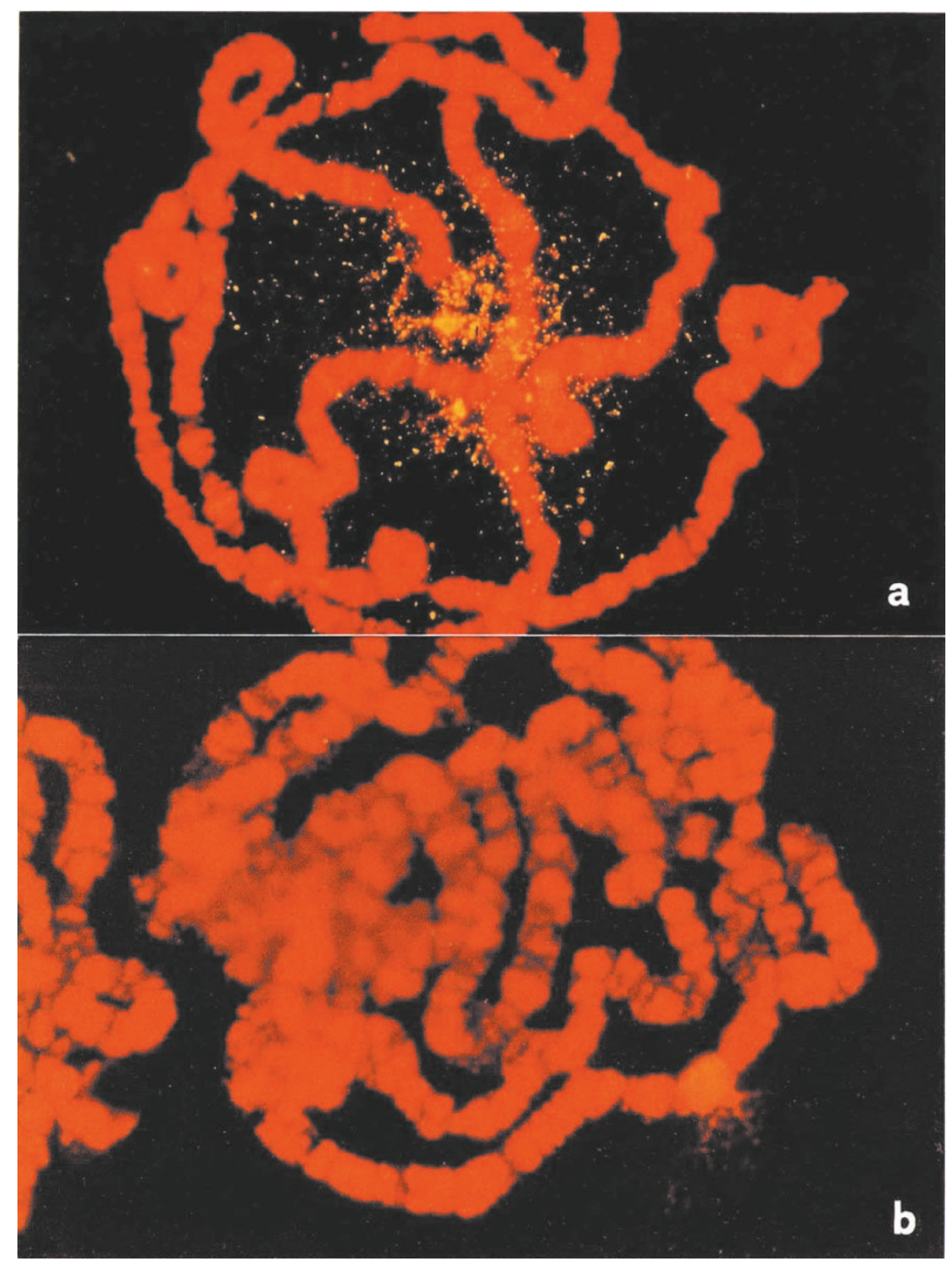


heterochromatic regions or adjacent to them. Association of rRNA genes with sex chromosomes has also been reported in many dipteran groups. In the medfly Ceratitis capitata and in several species of Drosophila ribosomal genes are localized on the X and Y heterochromatin (Spear, 1974; Endow \& Gall, 1975; Renkawitz \& Kunz, 1975; Bedo \& Webb, 1989). In Rhynchosciara and other Drosophila flies, in addition to the sex chromosomes, rRNA genes are also present on heterochromatic regions of other chromosomes (Gambarini \& Lara, 1974; Hägele \& Ranganath, 1983). A different pattern is found in species of Callyphora and Pseudodiamesia (Chironomidae) where rRNA genes are located on tiny dot chromosomes, largely heterochromatic (Beckingham \& Rubacha, 1984; Zacharias, 1984). However, at least in Drosophila, these dot chromosomes show close affinity with the $\mathrm{X}$ chromosome suggesting a derivation of dot chromosomes from sex chromosomes or vice versa (Sinibaldi \& Cummings, 1981). It is possible that the association between sex chromosomes and rRNA genes is a general feature in Diptera. Nevertheless, the association of ribosomal genes with sex chromosomes in Diptera could be only coincidental and the presence of ribosomal genes mainly related to the large amount of heterochromatin on the sex or dot chromosomes, as compared to the other chromosomes of the set.

Heterochromatin could have a functional role in rDNA under-replication (Grimm et al., 1984) although other factors are probably involved. In fact, in the polytene chromosomes of An. labranchiae the sex heterochromatin is under-replicated, forming a small body loosely connected to the centromeric regions of the other chromosomes. The rRNA genes are also underreplicated and dispersed in a network of filaments and granules within the nucleolus (Fig. 3a) as also found in Ceratitus capitata (Bedo \& Webb, 1989) and Drosophyla hydei (Pardue et al., 1970). On the other hand, in Or. pulcripalpis the rRNA probe hybridizes to a welldefined band, $4 \mathrm{C}$, of polytene chromosome I and does not seem to be under-replicated (Fig. 3b). This band is associated with the nucleolus and fibres and granules can be seen extending from the band into the nucleolus, probably with relation to transcriptional activity.

\section{Acknowledgements}

We are grateful to William C. Black for kindly providing the 18S rRNA probe, Frank Speleman and Roberta Vanni for technical advice on the FISH technique, Leonard E. Munstermann for helping in the collection of Orthopodomyia mosquitoes and Louis G. Mukwaya for the colony of Er. quinquevittatus.

\section{References}

BEDO, D. G. AND WEBB, G. C. 1989. Conservation of nucleolar structure in polytene tissues of Ceratitis capitata.(Diptera: Tephritidae). Chromosoma, 98, 443-449.

BECKINGHAM, K. AND RUBACHA, A. 1984. Different chromatin states of the intron ${ }^{-}$and type 1 intron $^{+}$rRNA genes of Calliphora erythrocephala. Chromosoma, 90, 311-316.

BLACK, W. C., IV, McLAIN, D. K. AND RAI, K. s. 1989. Patterns of variation in the rRNA cistron within and among world populations of a mosquito Aedes albopictus (Skuse). Genetics, 121, 539-550.

COluZZi, M., SABATINI, A., PETRARCA, v. AND DI DECO, M. A. 1979. Chromosomal differentiation and adaptation to human environments in the Anopheles gambiae complex. Trans. R. Soc. Trop. Med. Hyg., 73, 483-497.

DENNHÖFER, L. 1972. The correlation of linkage groups with chromosomes in the mosquito, Culex pipiens L. Chromosoma, 37, 43-52.

ENDOW, S. A. AND GALL, J. G. 1975. Differential replication of satellite DNA in polyploid tissues of Drosophila virilis. Chromosoma, 50, 175-192.

GALE, K. R. AND CRAMPTON, J. M. 1989. The ribosomal genes of the mosquito, Aedes aegypti. Eur. J. Biochem., 185, 311-317.

GAMBARINI, A. G. AND LARA, F. J. S. 1974. Under-replication of ribosomal cistrons in polytene chromosomes of Rhynchosciara. J. Cell Biol., 62, 215-222.

GILLINGS, M. R., FRANKHAM, R., SPEIRS, J. AND WHALLEY, M. 1987. $\mathrm{X}-\mathrm{Y}$ exchange and the coevolution of the $\mathrm{X}$ and $\mathrm{Y}$ rDNA arrays in Drosophila melanogaster. Genetics, 116 , 241-251.

GRIMM, C., KUNZ, W. AND FRANZ, G. 1984. The organ-specific rRNA gene number in Drosophila hydei is controlled by sex heterochromatin. Chromosoma, 89, 48-54.

HÄGELE, K. AND RANGANATH, H. A. 1983. The chromosomes of two Drosophila races: Drosophila nasuta nasuta and $D . n$. albomicans. III. Localization of nucleolar organizer regions. Genetica, 60, 123-128.

JAMES, A. A. 1992. Mosquito molecular genetics: the hands that feed bite back. Science, 257, 37-38.

KITZMILlER, J. B., FRIZZI, G. AND BAKER, R. H. 1967. Evolution and speciation within the Maculipennis complex of the genus Anopheles. In: Wright, J. W. and Pal, R. (eds) Genetics of Insect Vectors of Disease, pp. 151-120. Elsevier, Amsterdam.

KNIGHT, K. L. AND STONE, A. 1977. A catalog of the mosquitoes of the world (Diptera: Culicidae). The Thomas Say Foundation, vol. VI. Baltimore, MD.

KUMAR, A. AND RAI, K. S. 1990. Chromosomal localization and copy number of $18 \mathrm{~S}+28 \mathrm{~S}$ ribosomal RNA genes in evolutionarily diverse mosquitoes (Diptera: Culicidae). Hereditas, 113, 277-289.

LYCKEGAARD, E. M. AND CLARK, A. G. 1989. Ribosomal DNA and stellate gene copy number variation on the $\mathrm{Y}$ chromosome of Drosophila melanogaster. Proc. Natl. Acad. Sci. U.S.A., 86, 1944-1948.

MARCHI, A. 1988. Chromosomal evolution in the genus Orthopodomyia (Diptera: Culicidae). Abstracts XVIII International Congress on Entomology, p. 15. Vancouver, Canada. 
MARCHI, A. AND MEZZANOTTE, R. 1990. Inter- and intraspecific heterochromatin variation detected by restriction endonuclease digestion in two sibling species of the Anopheles maculipennis complex. Heredity, 65, 135-142.

MEZZANOTTE, R., FERRUCCI, L. AND CONTINI, C. 1979. Identification of sex chromosomes and characterization of the heterochromatin in Culiseta longiareolata (Macquart, 1838). Genetica, 50, 135-139.

MILLER, O. J. 1981. Nucleolar organizers in mammalian cells. In: Bennett, M. D., Bobrow, M. and Hewitt, G. M. (eds), Chromosomes Today, pp. 64-73. Allen \& Unwin, Boston.

MOTARA, M. A., PATHAK, S., SATYA-PRAKASH, K. L. AND HSU, T. C. 1985. Argentophilic structures of spermatogenesis in the yellow fever mosquito. J. Hered., 76, 295-300.

MUNSTERMANN, L. E., MARCHI, A., SABATINI, A. AND COLUZZI, M 1985. Polytene chromosomes of Orthopodomyia pulchripalpis (Diptera, Culicidae). Parasitologia, 27, 267-277.

PARDUE, M. L. 1985. In situ hybridization. In: Hanes, B. D. and Higgins, S. J. (eds) Nucleic Acid Hybridization: a Practical Approach, pp. 179-202. IRL Press, Oxford.

PARDUE, M. L., GERBI, S. A., ECKHARDT, R. A. AND GALL, J. G. 1970. Cytological localization of DNA complementary to ribosomal RNA in polytene chromosomes of Diptera. Chromosoma, 29, 268-290.

PARK, Y. AND FALLON, A. M. 1990. Mosquito ribosomal RNA genes: characterization of gene structure and evidence for changes in copy number during development. Insect Biochem., 20, 1-11.

RAO, P. N. AND RAI, K. S. 1987. Comparative karyotypes and chromosomal evolution in some genera of nematocerous (Diptera: Nematocera) families. Ann. Entomol. Soc. Am., 80, 321-332.

RENKAWITZ, R. AND KUNZ, w. 1975. Independent replication of the ribosomal RNA genes in the polytrophic meroistic ovaries of Calliphora erythrocephala, Drosophila hydei and Sarcophaga barbata. Chromosoma, 53, 131-140.

SAKAI, R. K., BAKER, R. H., RAANA, K. AND HASSAN, M. 1979. Crossing-over in the long arm of the $\mathrm{X}$ and $\mathrm{Y}$ chromosomes in Anopheles culicifacies. Chromosoma, 74, 209-218.

SPEAR, B. 1974. The genes for ribosomal RNA in diploid and polytene chromosomes of Drosophila melanogaster. Chromosoma, 48, 159-179.

SPELEMAN, F, VAN DER AUWERA, B., MANGELSCHOTS, K., VERCRUYSSEN, M., RAAP, T., WIEGANT, J., CRAEN, M. AND LERY, J. 1990. Identification and characterization of normal length nonfluorescent Y chromosomes: cytogenetic analysis, Southern hybridization and non-isotopic in situ hybridization. Hum. Genet., 85, 569-575.

SINIBALDI, R. M. AND CUMMINGS, M. R. 1981. Localization and characterization of rDNA in Drosophila tumiditarsus. Chromosoma, 81, 655-671.

SUMNER, A. T. 1990. Chromosome Banding. Unwin Hyman, London.

VITELLI, L., BATISTONI, R., ANDRONICO, F., NARDI, I. AND BARSACCHIPILONE, G. 1982. Chromosomal localization of $18 \mathrm{~S}+28 \mathrm{~S}$ and $5 \mathrm{~S}$ ribosomal RNA genes in evolutionarily diverse anuran amphibians. Chromosoma, 84, 475-491.

WHITE, G. B. 1980. Academic and applied aspects of mosquito cytogenetics. In: Blackman, R. L., Hewitt, G. M. and Ashburner, M. (eds) Insect Cytogenetics, pp. 245-274. Blackwell Scientific Publications, Oxford.

ZACHARIAS, H. 1984. Allocyclic behaviour and under-replication of the nucleolus chromosome in Pseudodiamesa (Chironomidae). Chromosoma, 89, 263-273.

ZAVORTINK, T. J. 1968. Mosquito studies. VIII. A prodrome of the genus Orthopodomyia. Contr. Amer. Entomol. Inst., 3, $1-221$. 